\title{
The Effect of Residual Stress on the Distortion of Gray Iron Brake Disks
}

\author{
M.W. Shin, G.H. Jang, J.K. Kim, H.Y. Kim, and Ho Jang
}

(Submitted April 16, 2012; in revised form July 31, 2012; published online October 2, 2012)

\begin{abstract}
Thermal distortion of gray iron brake disks due to residual stress and its effect on brake vibrations were studied. The residual stress of heat- and non-heat-treated gray iron disks was measured using neutron scattering. Dynamometer tests were performed to measure the friction force oscillation caused by the disk runout during brake applications. High-temperature tensile tests were carried out to find out possible plastic deformation due to residual stress during brake applications. The results showed that the average residual stress of the heat-treated disk $(47.6 \mathrm{MPa})$ was lower than that of the non-heat-treated disk (99.6 MPa). Dynamometer tests at high temperatures (up to $600{ }^{\circ} \mathrm{C}$ ) indicated that the residual stress pronounced the runout: the increase in disk runout after the tests for the non-heat-treated sample was more than twice that for the heat-treated sample. This difference correlated well with the neutron scattering results and the dimensional changes after a separate vacuum heat treatment. The high-temperature tensile tests showed severe reductions in yield strength at $600{ }^{\circ} \mathrm{C}$, suggesting that disks produced with no stress relaxation could be deformed during severe braking.
\end{abstract}

Keywords automotive, cast irons, heat treating, tribology

\section{Introduction}

Gray iron has been used to produce brake disks (or drums) since the early stages of vehicle development. This is because gray iron has good material properties for brake disks, such as high thermal conductivity, good machinability, wear resistance, good castability, excellent damping capacity, and low cost (Ref 1,2). On the other hand, it also has several undesirable properties for brake disks, such as relatively high specific gravity, dimensional instability at high temperatures due to residual stress, and inherent casting defects. While other materials such as aluminum-based metal matrix composites and ceramic-based carbon fiber composites have been developed as alternatives for brake disks, most vehicles still rely on the tribological properties of gray iron for brake disks, and much effort has been devoted to improving the shortcomings of gray iron disks, such as their excessive wear and corrosion, which are known to be root causes of brake judder (Ref 3-5).

In particular, brake judder has been an important issue in vehicle comfort in recent years, and various methodologies for reducing this low-frequency vibration have been used (Ref 6-8). It is known that disk warping or uneven disk thicknesses induce pulsation during brake applications. While it is known that the system robustness is important for reducing

M.W. Shin, G.H. Jang, and Ho Jang, Department of Materials Science and Engineering, Korea University, 1, 5-ga, Anam-dong, Sungbuk-gu, Seoul 136-713, Republic of Korea; and J.K. Kim, and H.Y. Kim, R\&D Division, Hyundai Motor Company and Kia Motors Corporation, Hwaseong-si, Gyeonggi-Do 445-706, Republic of Korea. Contact e-mail: hojang@korea.ac.kr. the amplification of the vibration, the major source of brakeinduced vibrations is the fluctuation of the friction torque produced at the sliding interface as a result of the dimensional variation of the disk. When the disk temperature is increased by friction heat during braking, the heat often causes dimensional instability of the disk, permanently modifying the runout or disk thickness variation (DTV) of a disk and producing brake judder. In particular, the residual stress, which is developed in a cast as a result of different local cooling rates, is known to be one of the important factors for reducing a disk's propensity for juddering, and stress relief by heat treatment is known to be an effective method for ensuring the dimensional stability of a disk at high temperatures.

Residual stress can be measured using several methods, including $\mathrm{x}$-ray scattering, hole drilling, indentation, and neutron scattering (Ref 9-11). The x-ray and neutron scattering methods are nondestructive, while the hole-drilling and indentation methods are semi-destructive. The measuring depth of an $\mathrm{x}$-ray is very small $(\sim 5 \mu \mathrm{m})$, and this method is only applicable to crystalline materials (Ref 9). The hole-drilling method measures the strain around the hole during drilling, and the indentation method is similar to a hardness measurement (Ref 9). However, the hole-drilling and indentation methods do not allow precise measurement of the residual stress in gray iron. This is because the microstructure of gray iron is a mixture of graphite flakes in a pearlitic steel matrix, and the multiphase nature of gray iron often produces large amounts of scattering in the data (Ref 1,2$)$. On the other hand, the neutron scattering method measures the residual stress of the ferritic phase in the gray iron along three principal directions to a depth of $10 \mathrm{~mm}$ with good repeatability.

The residual stress of brake disks was investigated by Ripley and Kirstein (Ref 12). They measured the residual strain using the neutron scattering method and showed that the relaxation of the residual stress in the disk could lead to disk distortion. Although the residual stress induces elastic deformation at 
room temperature, the tensile strength and hardness of gray iron decrease abruptly above $450{ }^{\circ} \mathrm{C}$, so that the maximum value of the residual stress can reach the yield stress of the gray iron at high temperatures (Ref 13,14), causing plastic deformation and permanent warping of the disk. In order to remove the residual stress of the brake disks, therefore, heat treatment to release the residual stress can be performed at high temperatures.

In this study, the residual stress was measured using a neutron scattering technique (Ref $9,15,16)$, and its correlation with the judder propensity was investigated by examining the effect of heat treatment on the microstructure of the gray iron and on the residual stress. Heat treatment was carried out in a vacuum to investigate the distortion produced by the relaxation of residual stress at high temperatures. While the disk warping during heat treatment was measured using a static DTV measurement unit, the dimensional change of the brake disks during braking was monitored using a dynamic DTV measurement unit.

\section{Experimental Procedures}

In order to investigate the dimensional change (or runout) of brake disks due to the release of residual stress, three different experiments were carried out. First, the residual strain of as-cast gray iron disks was measured using a neutron scattering method. Second, the change in runout was measured after vacuum heat treatment at $580{ }^{\circ} \mathrm{C}$. Finally, brake dynamometer tests were carried out to simulate the release of residual stress due to the large friction heat produced during severe braking. By comparing the three different test results, the effects of the residual stress on the changes in runout, DTV, and judder propensity were examined. Detailed experimental procedures are described in the following sections.

\subsection{Gray Iron Disks}

Commercial gray cast iron disks for a passenger car were used in this study. The carbon equivalent of the gray iron was 4.03, and the detailed composition is given in Table 1. The width of the rubbing surface of each disk was $57 \mathrm{~mm}$. Each disk had 50 straight vanes, and the disks were $302 \mathrm{~mm}$ in diameter and $28 \mathrm{~mm}$ in thickness. The vane size was $19 \mathrm{~mm}$ $(\mathrm{W}) \times 10 \mathrm{~mm}(\mathrm{H})$. An undercut was produced on the disk surface near the hat portion to prevent possible corning. Two different types of disks were prepared: heat-treated (Disk H) and as-cast (Disk NH) disks. To relax the residual stress, heat treatment was carried out by heating the disks at $580{ }^{\circ} \mathrm{C}$ for $5 \mathrm{~h}$, furnace cooling them from 580 to $300{ }^{\circ} \mathrm{C}$ at a rate of $40{ }^{\circ} \mathrm{C} / \mathrm{h}$, and air cooling them from $300{ }^{\circ} \mathrm{C}$ to ambient temperature. The heat treatment schedule is shown in Fig. 1. In order to reduce the effect of machining on the residual stress, the heat treatment was carried out on the as-cast disks before a final machining process.

The yield strength at elevated temperatures was measured using a tensile testing machine (Instron 5881) according to an
ASTM standard procedure (AFS-ASTM E21). The specimens were wire cut from the rubbing surface at the outer radius of Disk NH. The diameter of the specimens was $6.25 \mathrm{~mm}$, and the gage length was $32 \mathrm{~mm}$. A schematic of the specimen is shown in Fig. 2. The tensile tests were carried out at 25, 100, 200, 300, 400, 500, and $600{ }^{\circ} \mathrm{C}$ at a crosshead speed of $0.001 \mathrm{~mm} / \mathrm{s}$.

The microstructure of the gray iron was examined using an optical microscope (Leica DM1-LM). The graphite lengths of the disk were measured at outer, middle, and inner positions on the disk according to AFS-ASTM A247. The Brinell hardness test was carried out using a $10 \mathrm{~mm}$ diameter steel ball at a load of $3,000 \mathrm{~kg}$.

\subsection{Residual Stress Measurement Using Neutron Scattering}

The residual stress was measured from the diffraction peaks in the three principal orientations (i.e., radial direction [RD], hoop direction [HD], and normal direction [ND]) from a $2 \mathrm{~mm}$ (W) $\times 5 \mathrm{~mm}(\mathrm{~L}) \times 2 \mathrm{~mm}$ (D) gage volume of gray iron. The measurement was carried out using a beam of neutrons from a bent perfect crystal (BPC) Si (220) monochromator with a wavelength of 1.50-1.80 $\AA$. The beam was scattered in the sample, and the scattered neutrons were collected in a positionsensitive device (PSD). A schematic of the neutron scattering experiment is shown in Fig. 3.

The location in the disk of the specimen analyzed by neutron scattering is shown in Fig. 4. The figure also includes a cross section of the disk with the exact locations to be analyzed and the three principal orientations with respect to the specimen geometry. The reference specimen was also cut from the same location on the disk and heat treated to achieve a stress-free state. The heat treatment for the reference specimen was carried out by heating the specimen at $580{ }^{\circ} \mathrm{C}$ for $10 \mathrm{~h}$, after which it was slowly cooled in the furnace to ambient temperature.

The interplanar spacing of the (211) plane in ferrite was measured to compare the residual stress in the disks (Ref 12). The residual strain of the disk was calculated from the difference between the interplanar spacing of the target disks and that of a reference specimen using Eq 1 (Ref 9)

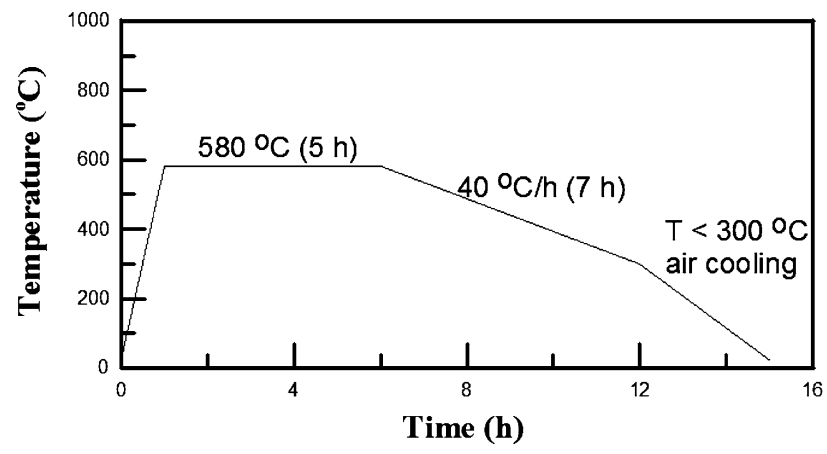

Fig. 1 Heat treatment schedule used to release residual stress in the gray iron disk

Table 1 Composition of the gray iron disks used in this study (wt.\%)

\begin{tabular}{lccccccccccc}
\hline $\mathbf{C}$ & $\mathbf{S i}$ & $\mathbf{M n}$ & $\mathbf{P}$ & $\mathbf{S}$ & $\mathbf{C r}$ & $\mathbf{M o}$ & $\mathbf{N i}$ & $\mathbf{C u}$ & $\mathbf{T i}$ & $\mathbf{F e}$ \\
\hline 3.26 & 2.31 & 0.77 & 0.094 & 0.048 & 0.35 & 0.017 & 0.043 & 0.37 & 0.048 & Bal. \\
\hline
\end{tabular}


$\varepsilon=\left(d-d_{0}\right) / d_{0}$,

where $d$ is the interplanar spacing obtained from the target disk and $d_{0}$ is the interplanar spacing of the reference specimen. The residual strain was converted into residual stress using Eq 2 (Ref 12)

$\sigma_{i}=\frac{E}{1+v}\left[\varepsilon_{i i}+\frac{v}{1-2 v}\left(\varepsilon_{x x}+\varepsilon_{y y}+\varepsilon_{z z}\right)\right]$,

where $E$ is Young's modulus (135.65 GPa) and $v$ is Poisson's ratio for gray iron $(=0.249)$. The elastic modulus and Poisson's ratio were measured using a resonance method according to an ASTM standard (AFS-ASTM standard E1876-07) (Ref 12, 17).

\subsection{Vacuum Heat Treatment}

The vacuum heat treatment was carried out to simulate the release of residual stress via disk distortion. The heat treatment

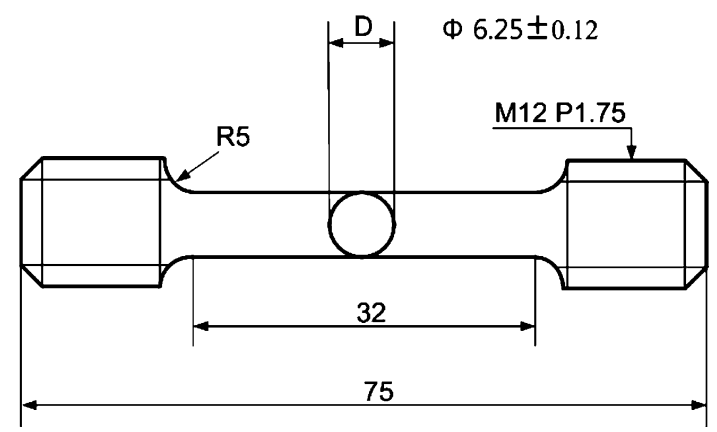

Fig. 2 Dimensions of the gray iron specimen used for tensile tests schedule consisted of furnace heating up to $580{ }^{\circ} \mathrm{C}$ followed by air cooling. The disks were hung on a steel rod to prevent dimensional changes caused by their own weight. Before and after the vacuum heat treatment, the runout and DTV were measured using a static DTV measurement unit (Describer$\left.\mathrm{S}^{\mathrm{TM}}\right)$.
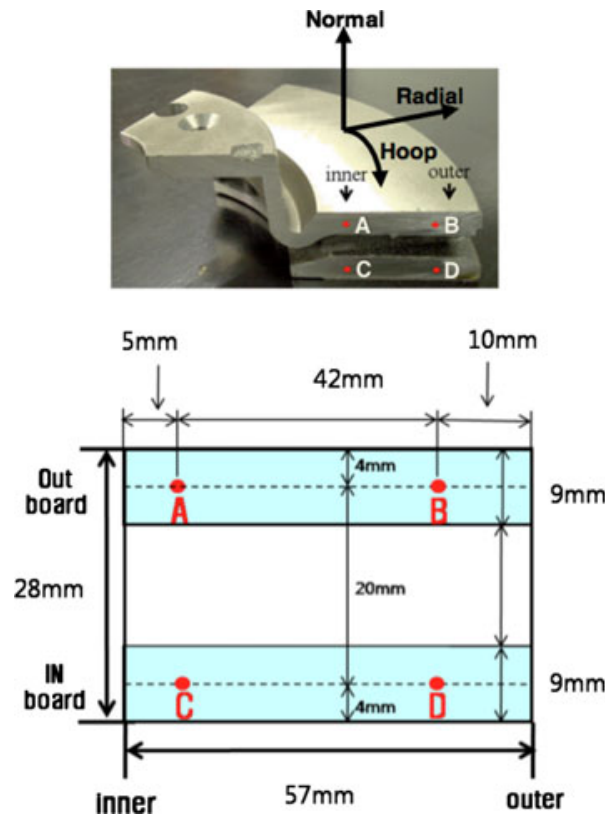

Fig. 4 Locations (A-D) used to measure residual stresses in the gray iron disk, along with the three principal orientations (normal, hoop, and radial)

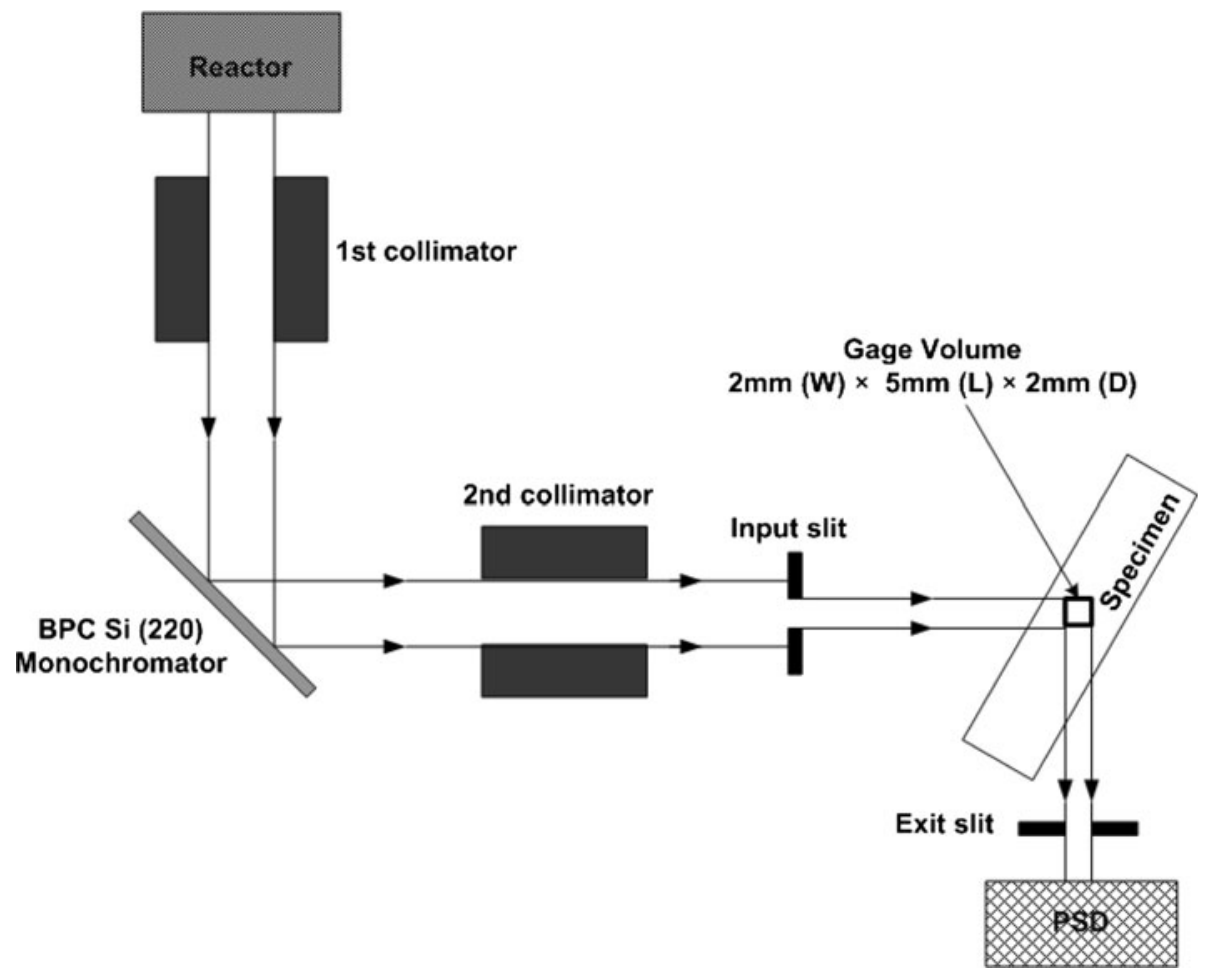

Fig. 3 Schematic of the neutron scattering method used to measure residual stress 


\subsection{Dynamometer Tests}

Dynamometer tests were carried out to simulate a hot judder mode using a single-ended brake dynamometer (Link Engineering Model 3000). The brake assembly used in this study comprised a commercial caliper with a single piston and was developed for a midsize passenger car. The test consisted of a preburnish, a 1st effectiveness check, a burnish, a 2nd effectiveness check, and juddering. The purpose of this test mode was to heat the disk above $580{ }^{\circ} \mathrm{C}$ and measure the changes in runout, friction coefficient, and disk temperature. The detailed dynamometer test procedure is listed in Table 2. The runout was measured by a static DTV measurement apparatus (Describer-S ${ }^{\mathrm{TM}}$ ) before and after the dynamometer tests. During the dynamometer tests, the runout was recorded by a dynamic DTV measurement unit (Describer-D ${ }^{\mathrm{TM}}$ ).

\section{Results and Discussion}

\subsection{Mechanical Properties of the Cast Iron}

It is known that the mechanical properties of gray iron are strongly affected by the lengths of the graphite flakes, which are in turn determined by the composition and cooling rate during casting (Ref 1). This is because the flaky graphite in the pearlitic matrix allows stress to be concentrated at the flake tips, so that it plays a crucial role in determining the tensile strength. The thermal conductivity of gray iron is also determined by the size and the distribution of the graphite flakes. This is an important property for brake disks, as the thermal diffusivity of the disk is critical for avoiding brake fade (loss of friction force at high temperatures) (Ref 18). The microstructure of the disk showed typical A-type graphite flakes (AFS-ASTM A247 designation) embedded in a pearlite matrix (Fig. 5). The maximum graphite lengths of the disk were measured at outer, middle, and inner positions on the disk according to AFSASTM A247. They were $180.5,200.8$, and $243.7 \mu \mathrm{m}$, respectively. There were slightly longer flakes in the inner section of the disk because of the difference in the cooling speed during casting. The pearlite microstructure of the disk, however, showed little difference among the different locations in the disk. The morphology and distribution of the graphite flakes and the pearlite microstructure also did not change after heat treatments. The microstructure and hardness (HB) of Disks NH and $\mathrm{H}$ did not change after heat treatment. The Brinell hardness values of Disks $\mathrm{NH}$ and $\mathrm{H}$ were 210 and 205, respectively.

The tensile strength of the gray iron was measured as a function of temperature. Figure 6 shows a drastic decrease of the yield strength above $600{ }^{\circ} \mathrm{C}$ : the yield strength at room temperature is $257.9 \mathrm{MPa}$, and it decreases to $66.7 \mathrm{MPa}$ at $600{ }^{\circ} \mathrm{C}$. Particularly noteworthy is the finding that the residual stress in the cast can plastically deform the disk during braking at elevated temperatures, leading to permanent distortion of the disk.

\subsection{Residual Stress in the Brake Disks}

The residual stress in a cast is known to be affected not only by locally different cooling speeds during casting but also by the final machining processes. This is because while the residual stress present in the cast is generated by the temperature gradient in the cast, it can be released by removing the constraint imposed by the surface when a portion of the surface is removed by machining. In order to study the effect of heat treatment on thermal distortion of a gray iron disk, the residual strain of the disk before and after the heat treatment was measured after final machining.

From the residual strain measured using a neutron scattering method for four different locations (Fig. 4) in the disk, residual

Table 2 Dynamometer test sequence used in this study to simulate severe braking conditions

\begin{tabular}{lcl}
\hline Test sequence & No. of Stop & \multicolumn{1}{c}{ Stop condition } \\
\hline Pre burnish & 10 & From $80 \rightarrow 2 \mathrm{kph}, 0.3 \mathrm{G}$ and $100 \mathrm{C}$ (IBT) \\
Effectiveness check & 5 & From $160 \rightarrow 80 \mathrm{kph}, 0.4 \mathrm{G}$ and $100 \mathrm{C}$ (IBT) \\
Burnish & 200 & From $80 \rightarrow 2 \mathrm{kph}$ at $0.3 \mathrm{G}$ and $100 \mathrm{C}$ (IBT) \\
Effectiveness check & 5 & From $160 \rightarrow 80 \mathrm{kph}, 0.4 \mathrm{G}$ and $100 \mathrm{C}$ (IBT) \\
Judder & 15 & From $160 \rightarrow 50 \mathrm{kph}$ at $100 / 200 / 300 / 400 / 500 \mathrm{C}(\mathrm{IBT})$ and at $0.2 / 0.35 / 0.5 \mathrm{G}$
\end{tabular}

IBT, initial brake temperature; G, deceleration; kph, kilometers per hour
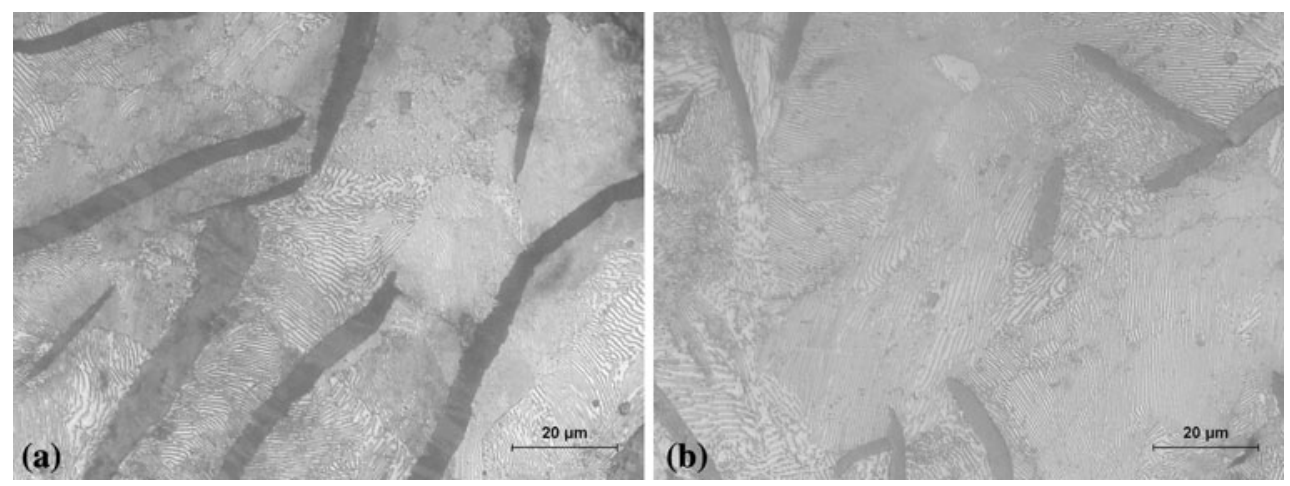

Fig. 5 Microstructures of gray iron Disks (a) NH and (b) H, exhibiting graphite flakes in a pearlitic matrix 
stresses were calculated along the three principal orientations (Fig. 7). The figure shows the residual stresses for tension (positive) and compression (negative), and no correlation was found between the location in the disk, the principal orientation, and the heat treatment with respect to the nature of the stress. On the other hand, the amount of stress was relatively small at location A, presumably due to the undercut (rain groove) near the hat section of the disk produced by machining. While the residual stresses were obtained from a single location in the disk and do not represent the stress distribution of the whole

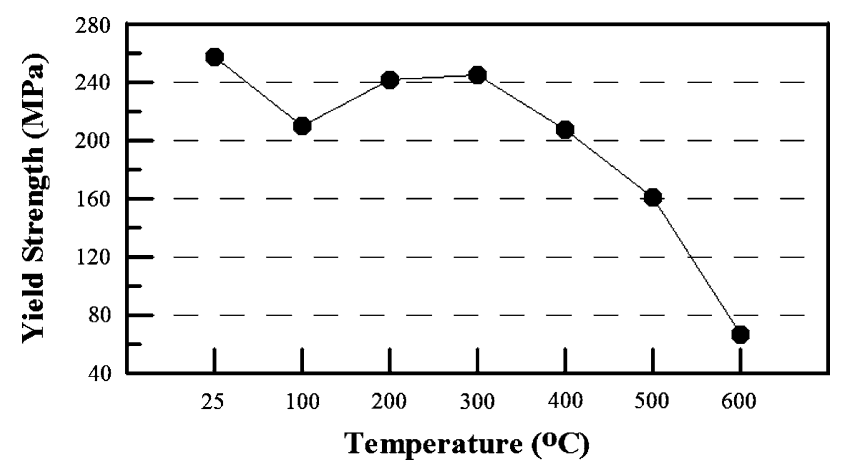

Fig. 6 Yield strength of gray iron measured at elevated temperatures

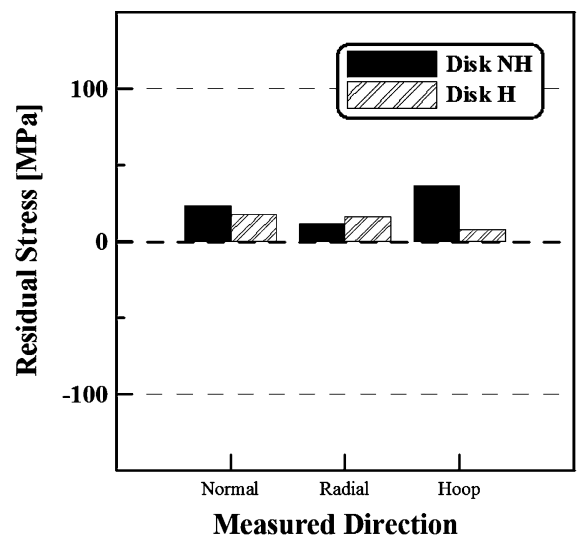

(a) Location $\mathrm{A}$

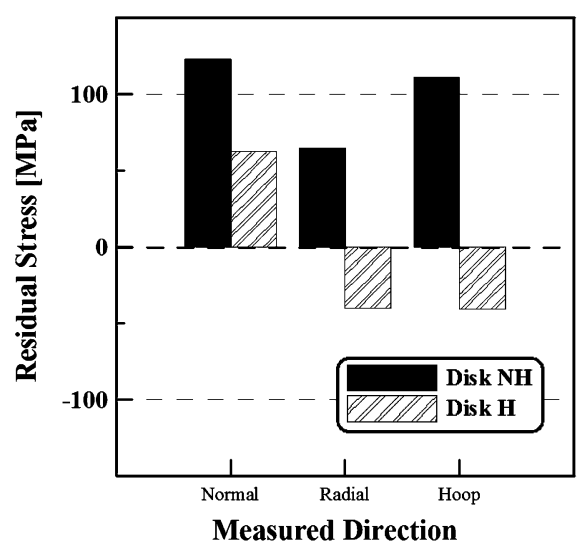

(c) Location $\mathrm{C}$ disk, they provide information about the relative amount of stress present in the disks with and without heat treatment.

To analyze the effect of residual stress on the disk distortion, the residual stresses in the normal orientation were compared first, as the deformation is easier along the normal orientation as it is least constrained compared to the other two directions. Figure 7 shows that the residual stresses along the normal orientation were reduced after heat treatment. The maximum residual stress before heat treatment was found at location $\mathrm{C}$ and was $123.5 \mathrm{MPa}$. This was reduced to $57.5 \mathrm{MPa}$ after stress relief heat treatment, indicating possible permanent deformation along the normal orientation when Disk NH is exposed to heat during braking. This is because the residual stress at point $\mathrm{C}$ of Disk NH is greater than the yield strength of gray iron at $600{ }^{\circ} \mathrm{C}$. On the other hand, the plastic deformation of the disk is not likely to occur in Disk $\mathrm{H}$, as the remaining residual stress after the heat treatment is smaller than the yield strength at high temperatures. Figure 7 also shows an inconsistent change of the stress state for both Disks $\mathrm{NH}$ and $\mathrm{H}$ in the radial and hoop directions, which is attributed to the vanes in the middle of the disks.

\subsection{Simulation of Thermal Distortion by Heat Treatment Using a Vacuum Furnace}

The dimensional change (warping) of the disk was monitored after the heat treatment in the furnace. This simulation

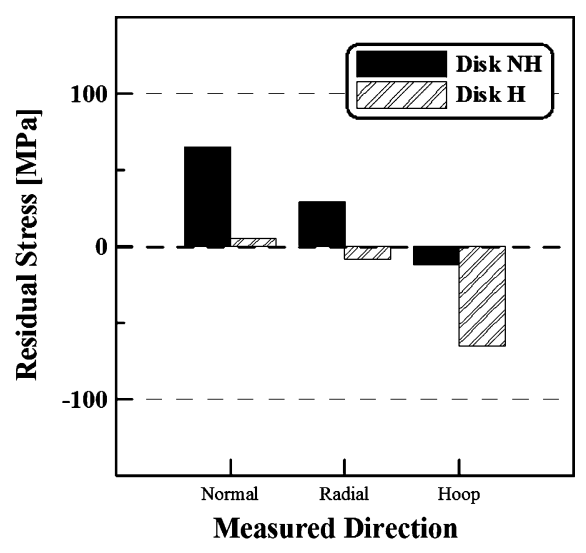

(b) Location B

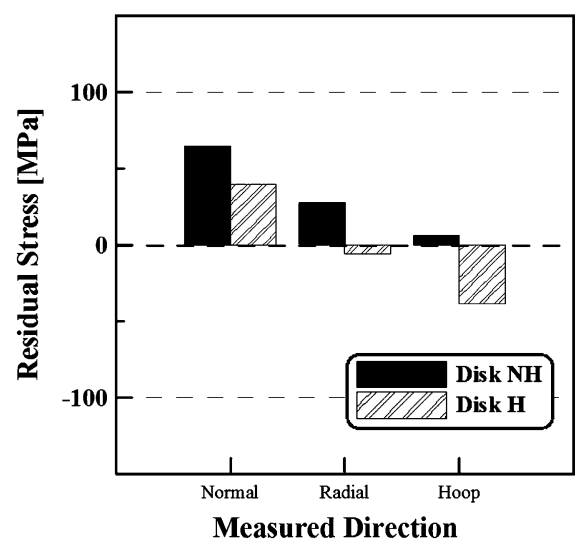

(d) Location D

Fig. 7 Residual stresses measured for the four different locations (A-D) illustrated in Fig. 5 along the three different principal orientations 

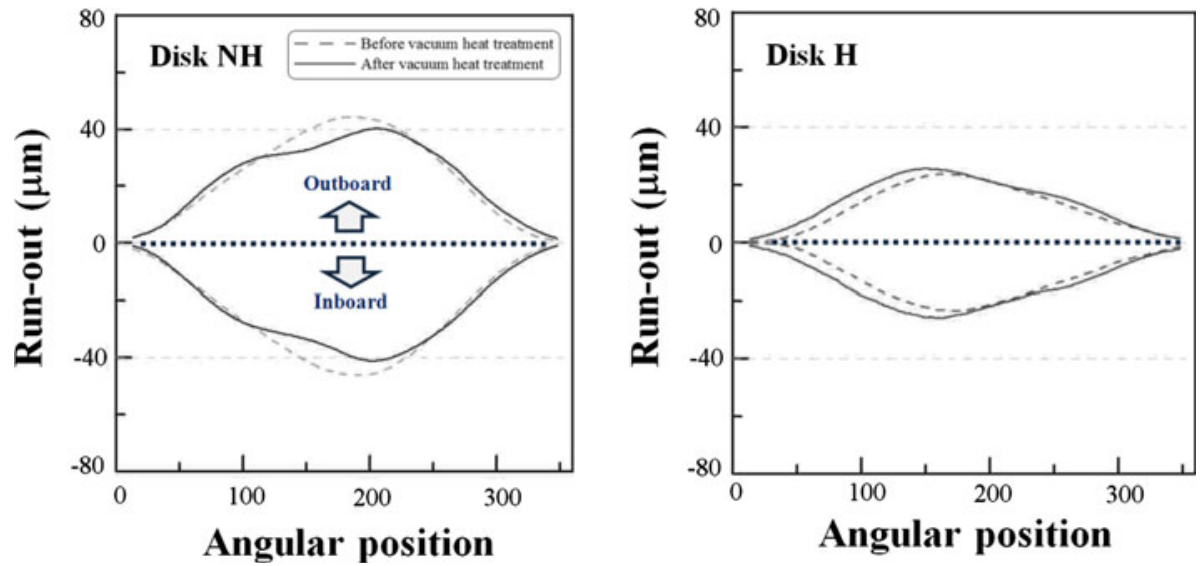

Fig. 8 Change in runout of the disks after vacuum heat treatments for Disks NH and $\mathrm{H}$

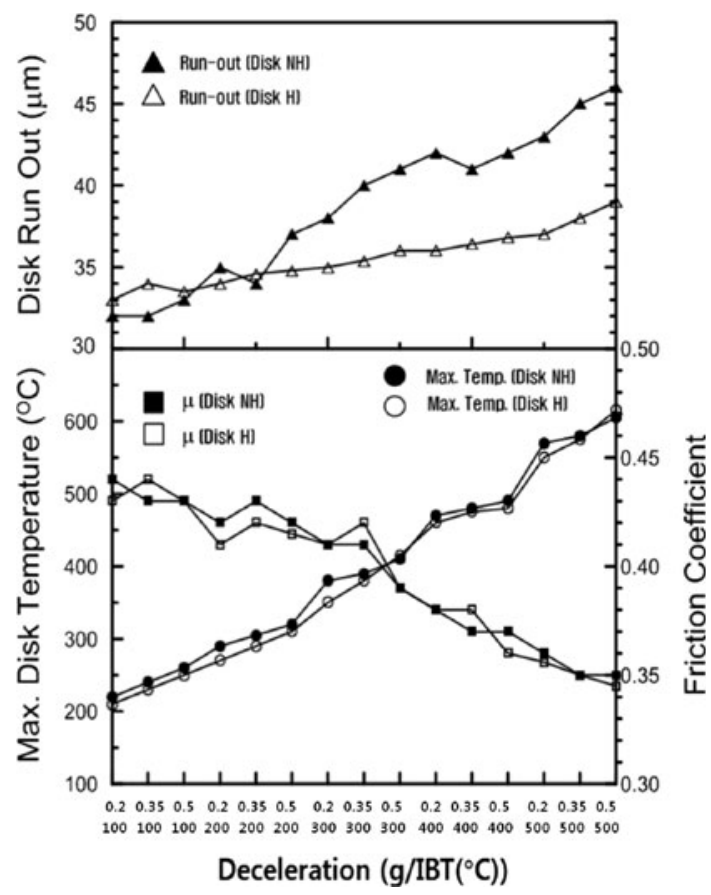

Fig. 9 Coefficient of friction, maximum disk temperature, and disk runout measured in situ under different braking conditions during the dynamometer tests using Disks $\mathrm{H}$ and $\mathrm{NH}$

was designed to evaluate the possibility of adopting a prescreening process for disk selection at an initial stage of brake system development by simulating the temperature under a severe braking condition. The distortions of Disks $\mathrm{NH}$ and $\mathrm{H}$ after the vacuum heat treatment are shown in Fig. 8. Among the dimensional changes, the maximum difference was about $8 \mu \mathrm{m}$ in Disk $\mathrm{NH}$ at an angular position of $150^{\circ}$, while $<2 \mu \mathrm{m}$ of dimensional change was observed in Disk $\mathrm{H}$ after heat treatment, suggesting that there are beneficial effects of the heat treatment resulting from the relief of residual stress. In particular, it was interesting to find that the vacuum heat treatment produced warping in Disk $\mathrm{NH}$, while Disk $\mathrm{H}$ underwent a uniform dimensional change. This indicates that the relatively large residual stresses of Disk NH in the normal orientation play important role in the non-uniform distortion of
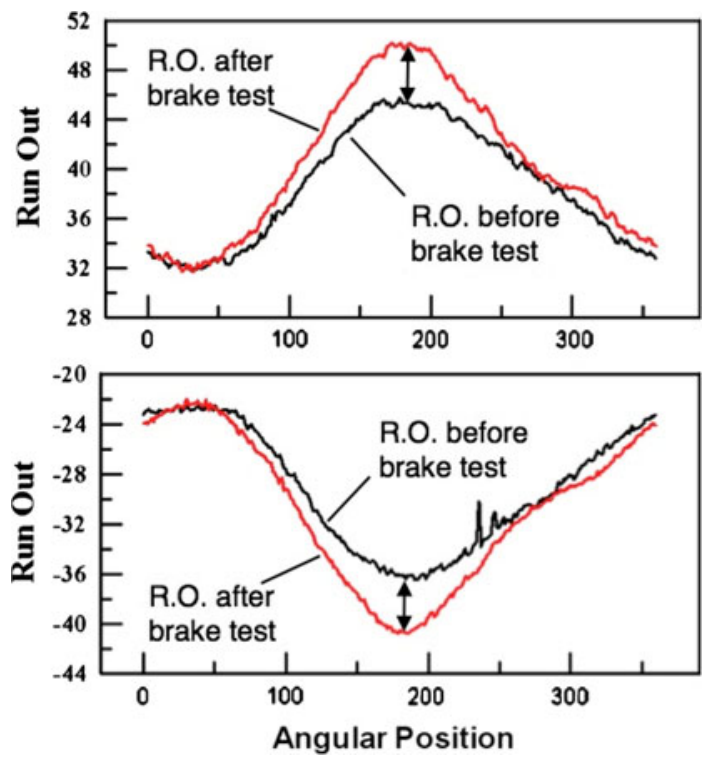

Fig. 10 Runout of the disks as a function of angular position before and after the high-temperature dynamometer tests for Disk $\mathrm{H}$. The arrows indicate the increase in runout measured at the edge of the disk

a disk during the release of the residual stress at elevated temperatures.

\subsection{Dimensional Change of the Disk During Dynamometer Tests}

The distortion of the brake disk during brake applications was analyzed by in situ monitoring of the runout during the dynamometer tests. The brake applications for disk distortion (judder test section) were carried out using the traditional performance checks and a burnish procedure, as shown in Table 2. The temperature of the disk during this test segment was increased by repeated brake applications at different decelerations and initial brake temperatures (IBT). Figure 9 shows the change in runout, the average coefficient of friction, and the maximum disk temperatures recorded during brake applications with different combinations of deceleration and IBT. This figure shows that the maximum disk temperature and the friction level are unchanged by the heat treatment of the 


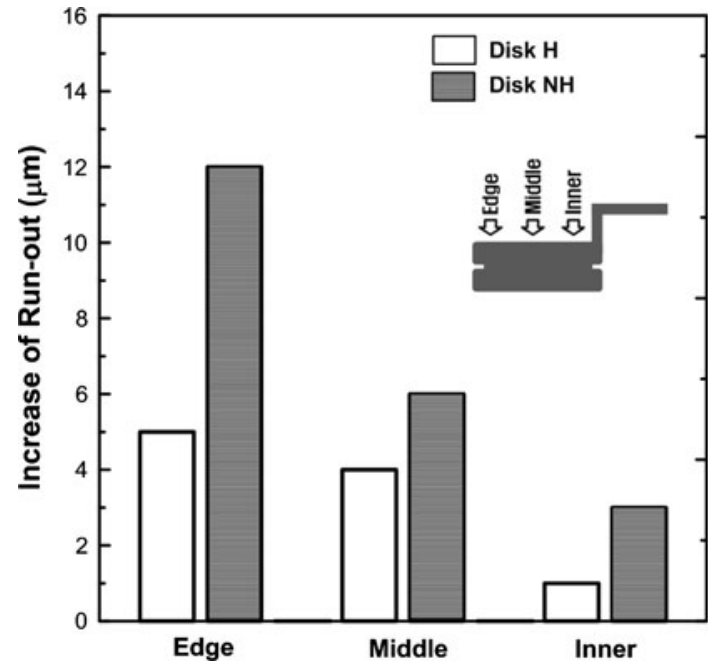

Fig. 11 Increase in runout of the disks after high-temperature dynamometer tests for Disks $\mathrm{H}$ and $\mathrm{NH}$. Measurements were carried out for three different locations (edge, middle, and inner, as shown in the inset) using a static DTV measurement unit

disks. However, the runout of Disk $\mathrm{NH}$ increased a lot compared to that of Disk H: the runout increment was $15 \mu \mathrm{m}$ for Disk NH and $6 \mu \mathrm{m}$ for Disk $\mathrm{H}$, suggesting that the residual stress significantly affected the permanent distortion of the gray iron disk. On the other hand, the small increase in the runout of Disk $\mathrm{H}$ indicates that some residual stresses still remain in the disk after the stress relief heat treatment used in this study.

The increase in the runout was also examined by measuring the runout values before and after the dynamometer test using a static DTV measurement unit. Figure 10 shows an example of the profile of the runout, presented as a function of the angular position on the disk. This figure shows that the runout permanently increased by approximately $5 \mu \mathrm{m}$ after the hightemperature dynamometer test when Disk $\mathrm{H}$ was used. The change in the runout was measured at three different circumferential locations (edge, middle, and inner positions) on the rubbing surface of the disk using a static DTV measurement unit. Figure 11 summarizes the increase in disk runout measured after dynamometer tests using Disks $\mathrm{NH}$ and $\mathrm{H}$. It clearly indicates that the effect of the residual stress in the normal orientation is significant and that this effect is pronounced at the edge location. This result suggests that the residual stress can induce thermal distortion of a gray iron brake disk and may increase the propensity of the disk to exhibit judder phenomena during brake applications after repeated braking at elevated temperatures.

\section{Conclusions}

The residual stress of gray iron disks was measured using a neutron scattering method to understand the effect of residual stress on the disk distortion. Two disks were used: one that had been subjected a conventional heat treatment to release the residual stress and one that had not. The disks were also heat treated in a vacuum furnace to simulate their possible distortion at high temperatures. Dynamometer tests were carried out, and the main emphasis was placed on the effect of the residual stress on the increase in runout, which is one of the main causes of brake judder. The results showed that the residual stress in the normal orientation produces the runout change of the disk after dynamometer tests at elevated temperatures. They also showed a significant increase in disk runout for the nonheat-treated disk, while the stress-relieving heat treatment reduced the disk distortion. The simulation of disk runout, performed by simply increasing the disk temperature in a vacuum furnace, shed light on a possible mechanism for prechecking the residual stress of gray iron disks in an early selection stage of brake components. The large increase in the runout along the circumference near the edge indicates the necessity for a more refined design of the casting process and the disk shape.

\section{Acknowledgment}

This study was supported by the Korea Research Foundation (KRF) through the National Research Laboratory Program (No. 2011-0020470).

\section{References}

1. I. Minkoff, The Physical Metallurgy of Cast Iron, Wiley, Chichester, 1983, p 175-277

2. L. Collini, G. Nicoletto, and R. Koněcná, Microstructure and Mechanical Properties of Pearlitic Gray Cast Iron, Mater. Sci. Eng. $A, 2008,488$, p 529-539

3. T. Tamasho, K. Doi, T. Hamabe, N. Koshimizu, and S. Suzuki, Technique for Reducing Brake Drag Torque in the Non-braking Mode, JSAE Rev., 2000, 21(1), p 67-72

4. S.K. Rhee and P.A. Thesier, Effects of Surface Roughness of Brake Drum on Coefficient of Friction and Lining Wear, SAE Technical Paper, 1972, Paper No. 720449

5. M.H. Cho, S.J. Kim, R.H. Basch, J.W. Fash, and H. Jang, Tribological Study of Gray Cast Iron with Automotive Brake Linings: The Effect of Rotor Microstructure, Tribol. Int., 2003, 36, p 537-545

6. S.K. Rhee, P.H.S. Tsang, and Y.S. Wang, Friction-Induced Noise and Vibration of Disc Brakes, Wear, 1989, 133, p 39-45

7. K. Doi, T. Mibe, H. Matsui, T. Tamasho, and H. Nakanishi, Brake Judder Reduction Technology-Brake Design Technique Including Friction Material Formulation, JSAE Rev., 2000, 21(4), p 497-502

8. H. Inoue, Analysis of Brake Judder Caused by Thermal Deformation of Brake Disc Rotors, 21st FISITA Congress, Belgrade, 1986, Paper No. 865131

9. J. Lu, Handbook of Measurement of Residual Stresses, Fairmont Press, Liburn, 1996, p 133-238

10. J.E. Wyatt, J.T. Berry, and A.R. Williams, A New Technique for the Determination of Superficial Residual Stresses Associated With Machining and Other Manufacturing Processes, J. Mater. Process. Technol., 2006, 171, p 132-140

11. C.O. Ruud, A Review of Selected Non-destructive Methods for Residual Stress Measurement, NDT Int., 1982, 15, p 15-23

12. M.I. Ripley and O. Kirstein, Residual Stress in a Cast Iron Automotive Brake Disc Rotor, Phys. B, 2006, 385-386, p 604-606

13. M.F. Rothman, High-Temperature Property Data: Ferrous Alloys, ASM International, Materials Park, OH, 1988, p 1.1-1.3

14. G.E. Dieter, Mechanical Metallurgy, 3rd ed., McGraw-Hill, New York, 1986, p 301-412

15. W. Woo, H. Choo, Do.W. Brown, Z. Feng, and P.K. Liaw, Angular Distortion and Through-Thickness Residual Stress Distribution in the Friction-Stir Processed 6061-T6 Aluminum Alloy, Mater. Sci. Eng. A, 2006, 437, p 64-69

16. K. Van Acker, J. Root, P. Van Houtte, and E. Aernoudt, Neutron Diffraction Measurement of the Residual Stress in the Cementite and Ferrite Phase of Cold-Drawn Steel Wires, Acta Mater., 1996, 44, p 4039-4049

17. B.A. Latella and S.R. Humphries, Young's Modulus of a $2.25 \mathrm{Cr}-1 \mathrm{Mo}$ Steel at Elevated Temperature, Scripta Mater, 2004, 51, p 635-639

18. S.K. Sinha and B.J. Briscoe, Polymer Tribology, Imperial College Press, London, 2009, p 506-532 